\title{
Studying Thought Processes of Online Peer Tutors through Stimulated-Recall Interviews
}

Marijke De Smet, Hilde Van Keer*, Bram De Wever, Martin Valcke Ghent University, Department of Educational Studies, Belgium

* Corresponding Author: Hilde Van Keer, Henri Dunantlaan 2, 9000 Gent, Belgium

\section{Homepages authors: \\ http://www.onderwijskunde.ugent.be/en/cv_desmet.htm \\ http://www.onderwijskunde.ugent.be/en/cv_vankeer.htm \\ http://www.onderwijskunde.ugent.be/en/cv_dewever.htm \\ http://www.onderwijskunde.ugent.be/en/cv_valcke.htm}

\begin{abstract}
The present study aims to explore the cognitive processes of older students during their peer tutoring support of freshmen engaged in asynchronous discussion groups. Stimulated-recall was applied to study the underlying motives for specific tutor behavior in the online discussions and to make tutors' concerns explicit. A grounded theory approach was used to analyze the interview transcripts. A constant comparative analysis of the data resulted in six issues associated with peer tutors' cognitive processing in relation to actual tutoring behavior: strategy use, reasons for intervention, experience with online discussions, evaluation of faculty support, satisfaction with tutor-tutee interaction, and evolution over time. Furthermore, the results point at tutor worries. A major dilemma concerns the persistent problem of deciding when, how exactly, and how frequently to intervene. A second tutor dilemma is associated with the multidimensional tutor role. Thirdly, peer tutors struggle with the fact they are not professionals so not expert in the learning materials.
\end{abstract}




\section{Introduction}

An extensive body of peer tutoring studies documents the impact of introducing peer tutoring programs within a face-to-face context (see e.g., Carroll, 1996; Duran \& Monereo, 2005; Topping, 1996; Webb, 1992). However, apart from the recent work of McLuckie and Topping (2004) and De Smet, Van Keer, and Valcke (2008), research into online peer tutoring is relatively scarce. Moreover, in the limited number of studies available, the thought processes underlying the tutor's online facilitation approaches in the actual management of younger peers' learning processes is rarely addressed. The present study aims to fill this research gap by focusing on the thoughts and reflections of older students during their online peer tutoring support of freshmen. This purpose may assist in controlling the commitment and responsibility on the older peers in the tutoring experience. As it is not common to analyze thought processes by means of a survey or building on questionnaires, qualitative interpretative research is chosen. In line with the work of Bennett and Marsh (2002) on training programs for online tutors, fourth-year university students, who participated in the present study as cross-age tutors, are engaged in stimulated-recall to reflect on their online tutor role. Additionally, this technique is most useful for generating research-based understanding of peer tutors' thoughts on their field experiences. Moreover, the information obtained from the interviews can identify elements valuable for the design of future tutor training programs.

\section{Theoretical background}

Online facilitation can be described as "the act of managing the learners and the learning through an online medium" (Backroad Connections Pty Ltd, 2002, p. 2). It is frequently referred to as 'online moderation' or 'e-moderating' (Bonk, Wisher, \& Lee, 2004; Paulsen, 1995; Salmon, 2000). In online learning this management is usually taken care of by a teacher or a staff tutor. However, e-moderating can be an older peer task as well. In the study of McLuckie and Topping (2004), for example, student tutors were introduced in an interactive online learning environment to give their peers ongoing content and/or process-related support. This type of collaborative learning, in which "people from similar social groupings who are not professional teachers help each other to learn, and learn themselves by teaching" (Topping, 1996, p. 322), is called peer tutoring. Peer tutoring is further characterized by "specific role taking as at any point someone has the job of tutor while the other(s) are in the role of tutee(s)" (Topping, 1996, p. 322). Within the scope of the present study, the facilitating role performance of cross-age online tutors is of special interest.

A number of researchers acknowledge that online facilitation behavior is generated by a cognitive activity at the same time that it generates this activity (Darvin, 2006). This point of view stresses the impact of both cognitive activity and context variables on online facilitation behavior, and therefore, the situated nature of online facilitation (Darvin, 2006; Lave \& Wenger, 1991). Within the broad area of research on peer tutoring little empirical evidence is found in view of gaining insight into tutors' cognitive activity when facilitating younger peers' collaborative learning. Although it has been shown that during the actual task of supporting, facilitators learn as they reason (Zohar, Degani, \& Vaaknin, 2001), generate instructional explanations, and monitor their own understanding (Chi, Siler, \& Jeong, 2004; Topping, 1996; Topping, 2005), the actual thought process of peer tutors' during this practice is rarely studied. In their exploratory study, Solomon and Crowe (2001) aimed at presenting an overview of the perceptions and concerns of student tutors in a carefully organized face-toface and problem-based learning program. The results of this study indicated that peer tutors convey a sense of worry and a feeling of responsibility for ensuring that their colleagues addressed the tutorial objectives adequately. 
Bennett and Marsh (2002) also made a valuable suggestion after surveying the research literature on being an effective online tutor. During the in-service training program that they implemented, the staff tutors were given the opportunity to 'observe' their own online tutor role through online teaching observation and a mentor-facilitated discussion. Involving tutors in self-observation, stimulated-recall interviews, or discussions about the nature and complexity of online facilitation processes fits in with the approaches adopted in 'teacher thinking' and 'teaching practice' research (Udvari-Solner, 1996) as well as research exploring beliefs underlying teachers' actions (Samuelowicz \& Bain, 2001; Zohar et al., 2001). In general, a reflective, developmental, and inquiry-oriented view on the teaching practice and teaching career underlies the broad research field on 'teacher thinking'. In particular, from the mid-1980s, educational researchers began to focus on non-behavioral components of the teaching process, such as (1) teachers' beliefs about classroom, students, school, and learning; (2) teachers' decisions for designing and presenting a teaching activity; (3) teachers' perceptions on classroom teaching affairs; and (4) teachers' roles and their self-images (Kagan, 1995). In their expectancy-value model on motivation, Wigfield and Eccles (2000) stressed that, besides contextual circumstances, cognitive processes, and beliefs affect teaching performance. According to Valcke, Sang, Rots, and Hermans (in press), the feedback loop in the expectancy-value model is of critical importance. The feedback loop illustrates how teachers' teaching performance is part of a persistent interplay with context variables, cognitive processes, and personal beliefs.

In line with the work of Hargreaves and Fullan (1998) and Wigfield and Eccles (2000) on teacher thinking, we assume that it is what tutors think and what tutors do at the level of the online environment that ultimately shapes their kind of tutoring and learning. Within the context of the present study on online peer tutoring behavior, cognitive processing in relation to actual behavior takes a central position. In this respect, capturing a portrait of the tutor's thinking during practice may contribute to previous behavior-oriented studies about online peer tutoring (De Smet et al., 2008; McLuckie \& Topping, 2004). The importance of this broader orientation towards tutoring performance is stressed in view of the conclusions that might be derived for the improvement of future online peer tutoring practices. Furthermore, a cognitive processing orientation towards tutoring behavior may allow future tutor trainers to identify and develop solutions to the challenges and paradoxes of authority embodied in peer tutoring (Chappell, 1995; Solomon \& Crowe, 2001). From the tutor's learning perspective, requirements for recalling their thoughts may encourage tutors to reflect on their current practice and advance exploration of new perspectives and tutoring strategies (Bennett \& Marsh, 2002; Udvari-Solner, 1996). Accordingly, these reflections may offer research-based evidence of the learning of the tutor as suggested in earlier research on peer tutoring (Chi et al., 2004; Topping, 1996; Topping, 2005).

\section{Research aims}

In this study we intend to draw a more complete picture of peer tutoring activities. Therefore, we build on the wide scope of teacher thinking studies (Hargreaves \& Fullan, 1998; Kagan, 1995; Samuelowicz \& Bain, 2001; Udvari-Solner, 1996; Wigfield \& Eccles, 2000; Zohar et al., 2001) and apply points from these studies of teacher thinking to the situation of students engaged in peer tutoring. This means that context variables and non-behavioral components such as beliefs, decisions, perceptions, and self-concepts tend to be associated with the actual tutoring behavior. Our study responds to the need to understand the specific gains and reflections accruing from the tutoring process. Uncovering a broad spectrum of specific peer tutor thoughts underlying their actual online peer tutor behavior and facilitation is the main purpose of the present study. More specifically, the following objectives directed our research. First, this study aims to identify and to make explicit specific themes or issues raised 
by student tutors facilitating online discussions. Secondly, we intend to study the concerns of online peer tutors as this might be helpful to direct future tutor training practices.

\section{Method}

\section{Participants}

The present study was set up during the first semester of the academic year 2006-2007. Fiftyseven fourth-year Educational Science students participated, of which 53 were female and 4 were male, aged between 22 and 25 years. These students were enrolled in a 6-credit educational internship. During this internship they take up the role of peer tutor facilitating asynchronous discussion groups. In view of their online facilitation role, tutors received a specific training which is discussed below.

\section{Research context}

The asynchronous discussion groups were a formal component of the 'Instructional Sciences' 7-credit course, which is part of the first-year bachelor of Educational Sciences' curriculum. In the present study, the general task for the cross-age tutors was supplying support during freshmen's online task-based interaction. More specifically, during 8 weeks the freshmen worked on four successive authentic tasks related to four course themes: behaviorism, cognitivism, constructivism, and higher-order thinking in educational settings. Each assignment lasted two weeks. The tutors worked in 28 tutor pairs (except for one 3-person team), facilitating the same group of 12 to 14 freshmen students throughout all assignments. The co-tutorship format implied tutors took turns at supporting the online discussion group. During a complete discussion theme one tutor was unchangeably in charge, while the nonactive tutor followed the online discussion in the background, monitored the interaction, and shared ideas in view of the online facilitation acts if necessary.

\section{Procedure}

To structure the online facilitation, and to meet basic tutor quality requirements, the following components were built in to the support of all peer tutors: (1) tutor training, (2) stimulatedrecall interviews, (3) focus groups, (4) keeping a tutor diary, and (5) writing a personal internship report.

(1) Tutor training: Tutors participating in the present study already had experiences with comparable asynchronous discussion assignments during their own first bachelor year. However, at the time when the present tutors were freshmen, no cross-age peer tutors were assigned to the discussions. In this respect, the tutors in the present study were not involved earlier in a peer tutoring process. However, by being engaged themselves in comparable assignments and going through a process of knowledge construction in asynchronous discussion groups, the tutors already had developed some prior knowledge and skills regarding collaborating online, managing online discussions, ... Therefore, the tutor training did not have to start from scratch and could build on these acquired experiences. Student tutors needed however an introduction to the dynamics, skills, and techniques of online facilitating the discussion processes of younger students. Hence, a compulsory tutor training was organized during a three hour face-to-face session prior to the actual tutoring. The tutor training format included pre-service practice. At the end of the training, tutors received an indepth introduction to the CSCL-environment and a website was set up supporting the administrative and logistical issues related to the online facilitation during the next 8 weeks. The tutor training was supplemented by a tutor manual with background information as well.

(2) Stimulated-recall interviews: the individual 57 tutors were involved in two stimulatedrecall interviews, which focused on recalling tutors' thinking processes prior to and during their tutoring activities. Further information about stimulated-recall is presented below.

(3) Focus groups: in order to supervise tutors' performance and to improve peer tutoring activities through feedback, every two weeks focus groups were organized. These face-to-face 
meetings were set up in small groups of approximately ten tutors bringing together tutors from the same tutor training condition.

(4) Keeping a tutor diary: by means of keeping a diary, tutors were required to write down reflections about their activities on a daily basis. More specifically, they were asked to reflect on their position, role, and concrete interventions. An example of what could be expected from the tutors in terms of this diary was made available on the tutor website.

(5) Writing a personal internship report: at the end, tutors were required to write a concise personal internship report consisting mainly of critical reflections about their tutoring activities and the identification of indicators of personal progress (Seale \& Cann, 2000).

Data collection and sampling

Lyle (2003) argued that coaching presumes cognitive skills in which thinking and decisionmaking is paramount. Therefore, studying the nature of online facilitation and especially the cognitive processes underlying the tutoring activities may allow the adoption of qualitative methodological approaches. Lyle (2003) studied sports coaches' cognitive activity and tried "to design an investigation which (a) adopted a holistic approach; (b) used data gathered from a naturalistic setting; (c) engaged with the cognitive system and its interaction with the environment; and (d) addressed the challenge of inferring cognitive organization from individual and retrospective techniques" (ibid, p. 868). To achieve this goal in the present study, we adopted stimulated-recall. This research method makes it possible to elicit peer tutors' decision-making, beliefs, dilemmas, and goals which are vital to understand what they do in the online discussion group, and why they do so. This approach is also in line with the work of Calderhead (1981) who stated that the identification of teachers' thoughts and decision-making by stimulated-recall, and the reasons they have for acting as they do, could provide essential information in the description of teaching processes in naturalistic research. On top of the methodological perspectives, in the present study tutors were also required to engage in stimulated-recall as an opportunity to reflect on and learn from their online tutor role. Although the stimulated-recall method has been used extensively in classroom-based research about teaching (Dunkin, Welch, Merritt, Phillips, \& Craven, 1998; McBride \& Bonnette, 1995; Schepens, Aelterman, \& Van Keer, 2007; Stoffels, 2005), the use of nonvideo based approaches that build on both written, asynchronous, and peer communication has yet not been reported in the literature.

The procedure adopted by the researcher in managing the stimulated-recall interviews builds on a series of open-ended questions presented to the tutor immediately after reviewing his tutor contributions in the discussion group. For instance, the interviewer pointed to single online contributions and asked the tutor to remember and report what he/she actually thought just before and during writing this tutoring comment. Another open-ended question asked for the extent to which the tutor intervened deliberately. On average, the stimulated-recall interviews lasted twenty minutes per tutor. To gather information about the validity of the interview procedure, a number of additional questions were asked about the difficulty in reliving the thinking processes (i.e., 'were you able to relive what you thought and felt just before and during intervening?'). Since the stimulated-recall technique was also introduced as a type of 'clinical supervision' (Wallace, 1991, In: Bennett \& Marsh, 2002), the interviewer finished the session by inquiring as to whether or not the tutor needed specific faculty help in future tutoring sessions. Furthermore, the researcher added personal comments or memos as an initial written form of reflecting on the data being gathered (Strauss \& Corbin, 1990). In general, field notes permit us to make the qualitative research process more explicit.

In order to analyze the interview data, each stimulated-recall interview was audio-taped and a 'purposeful sample' of the recordings was transcribed. Coyne (1997) defines purposeful sampling as "selecting information-rich cases for study in depth" (p. 624). As for Cutcliffe (2000), "purposeful sampling involves the calculated decision to sample a specific locale 
according to a preconceived but reasonable initial set of dimensions" (p. 1477). In this respect, 45 interviews were chosen for data analyses from a set of 112 interviews (i.e., 28 tutor pairs over four discussion themes). In order to generate rich information on the type of phenomena which needed to be studied (Miles \& Huberman, 1994), purposeful sampling was based on gender and discussion theme variables. Taken into account that only 4 male tutors were involved in the present study, we selected primarily female tutors in the purposeful sampling of the interviews. However, a male tutor was selected as well, to include also this perspective. Transcriptions of the interviews were linked to the four consecutive discussion themes: theme $1=12$, theme $2=11$, theme $3=10$, and theme $4=12$.

Data analyses

An in-depth qualitative analysis was carried out in order to map the large variation in topics being raised by online peer tutors in the data. Therefore a grounded theoretical approach was adopted (Glaser \& Strauss, 1967; Strauss \& Corbin, 1990). Cutcliffe (2000) gives the following description of this analysis approach: "Grounded theory is a theory that will fit the situation being researched and work when put into use. By fit Glaser and Strauss mean that the categories must be readily (not forcibly) applicable to and indicated by the data under study. By work they mean that the categories must be meaningfully relevant and be able to explain the behavior under study" (p. 1477, italics his own).

To support the qualitative analysis, the Atlas.ti 5.2 software tool was used to organize the interviews, compare data, and construct knowledge relating to the topics arising during peer tutors' retrospective talk (Marsh, 2001). The actual coding of the topics implied the adoption of an interpretative and cyclical approach to review the coding categories and the sections studied earlier until a rich final and saturated picture has been developed (Zafeiriou, 2003). This process of attempting to saturate coding categories with case examples in order to support their relevance is often called the 'constant comparative method' (Strauss \& Corbin, 1990). To give an example of this method later known as Grounded Theory, our results apply to distinctive issues and dilemmas negotiated by online peer tutors during stimulated-recall. The initial coding resulted in 24 categories identifying a blend of events, strategies, decisions, beliefs, perceptions, attitudes, self-images, feelings, and concerns related to the students' experiences as online peer tutors. Thanks to a closer computer-supported and iterative examination procedure, the 24 categories developed beforehand were once again examined and clustered to form themes. Finally, the open-coding technique (Strauss \& Corbin, 1990) illuminated six tutor issues and five tutor challenges, and resulted in a general analytical framework that had theoretical and practical relevance in relation to our research setting.

\section{Results}

A qualitative analysis of the tutor interview sample drawing on Grounded Theory revealed specific thoughts of student tutors during a series of online tutoring activities. In what follows, these reflections are divided into main issues and specific tutor concerns. To illustrate their frequency, the total number of interviews and the number of statements within these interviews referring to and/or exemplifying one specific issue is reported, together with translated fragments of the tutor's disclosure.

\section{Issues raised by tutors}

A constant comparative analysis of the data resulted in the identification of six main issues associated with peer tutors' thoughts on their actual online facilitation acts: (1) strategy use, (2) reasons for intervention, (3) experience with online discussions, (4) evaluation of faculty support, (5) satisfaction with tutor-tutee interaction, and (6) evolution over time. These distinct thematic issues are outlined in more detail below. 


\section{Strategy use}

Almost all tutors mentioned that they applied particular tutoring strategies (189 statements over 40 interviews). A typical example of a tutoring strategy concerns: giving a compliment to the student prior to making a comment or posing a question. Other strategies frequently mentioned and adopted by the tutors were: modeling how to induce (counter)arguments, how to elicit summaries, and how to promote discussion on a topic; keeping an eye on the structure of the discourse; encouraging students to participate; controlling for understanding; and providing or inviting for examples.

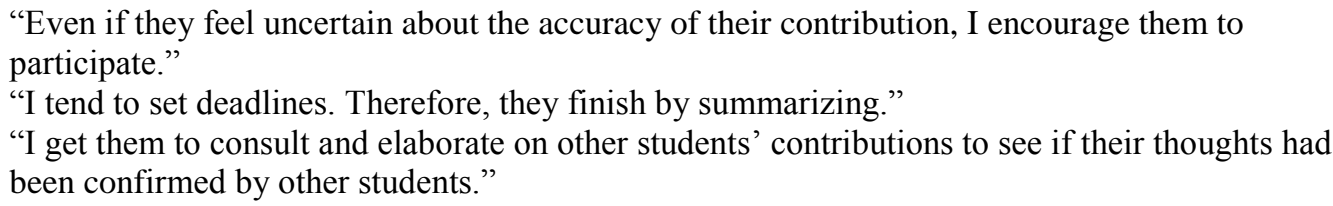

Moreover, when talking about their strategy use, tutors applied a large variety of tutoring metaphors (72 statements over 30 interviews) to illustrate personal skills, beliefs, or thoughts associated with their online facilitation role. For instance, a student compared her computersupported facilitation role with "being on call". One tutor associated his overall peer tutor role with three main tasks of a skipper:

"Creating enough swell at sea, passing on the helm, and taking over the helm when the ship is threatened to sink."

Reasons for intervention

Tutor reactions to the interview questions revealed that they have specific reasons that direct a decision to intervene in a discussion at a certain moment. They mention: 'keeping dialogue on track, elaboration on a topic, time or conflict management, indicating content mistakes or misunderstandings, seizing the chance to build on the input of freshmen, answering questions, and introducing individual experiences or beliefs'.

"I was thinking that when the discussion seems unclear for me as a tutor, there is a huge chance that this would be the same for the other participants."

"As there came no answer on that, in my opinion, important question, I decided to elicit the solution myself."

"Not everyone is intrinsically motivated to participate, so I started with an opening question."

"I felt some controversy between two levels of theory and practice, so I clarified this issue with an example."

In contrast to decisions to intervene (92 statements over 33 interviews), tutors also decided regularly not to jump in (37 statements over 21 interviews).

"I had no reason to complain, thus I thought to wait."

"They are doing very well, so I decided not to intervene."

"They took a slow start, but I preferred to let them work things out independently."

Experience with online discussions

Most student tutors did build on their personal experiences with online discussions (51 statements over 22 interviews). They referred explicitly to the weaknesses observed in their earlier experiences: unstructured discussions, low participation levels, limited understanding of individual students, and non-content-related contributions. This resulted in conscious decisions to pay attention to social and organizational support, such as giving compliments, sticking to the planning, and promoting a group decision that is clearly related to the actual completion of the group assignment. 
"I remember it is useful to make and agree to a planning in online discussions."

"In comparison with my first-year discussion group, it seems that the tutees stick more to the assignment."

"Coming to the computer class at university to post a message in the discussion group is a barrier for first-year students."

Evaluation of faculty support

The tutors stressed that they were satisfied with their participation in the focus groups that were set up for tutors (21 statements over 13 interviews). The majority of the tutors found the peer feedback and the advice they received during the focus group sessions inspiring to solve problems encountered in subsequent tutoring activities and to put new ideas into practice. In addition, many tutors indicated that they could build on faculty support.

"During the focus groups for tutors, I was initially advised to apply the first three steps of emoderating. Hence, I geared my tutoring activities to this suggestion."

Satisfaction with tutor-tutee interaction

Many tutors expressed strong feelings of satisfaction when their tutees were participating and negotiating well (47 statements over 23 interviews). Especially when they observed that firstyear students took into account their contributions, tutors explicitly expressed appreciation. The following example is related to tutees showing meaningful thinking:

"I do appreciate that this first-year student clearly defends his opinion by means of an elaborated argumentation. I reinforced his behavior and asked the group whether they agreed or not."

Unfortunately, a minority of tutors reported opposite feelings as well. They found it frustrating and irresponsible of tutees when they ignored the tutor's posted message (18 statements over 12 interviews). Those tutors reported this disillusionment especially in relation to the final discussion theme. In this final theme it appeared that tutees were much less engaged in the online discussions and less responsive to tutors' contributions, because of the high workload they experienced due to the discussion assignment and additional tasks for other courses so close to the examinations of the first semester.

Evolution over time

Finally, in the stimulated-recall sessions, the tutors also mentioned issues related to changes in their thoughts over time (12 statements over 5 interviews). Since both tutors and tutees got more experienced in dealing with the online learning environment, some tutors felt somewhat superfluous during the later stages of the tutoring period. Other tutors were better able to deal with this evolution in the online discussions. They effaced themselves partly, invested more time in observing the ongoing discourse, and intervened only occasionally during the final discussions.

"I neither made the threaded structure nor the planning myself. At this time, I am sure they can do it themselves."

At that moment, they especially tried to stimulate critical thinking about the learning content and the group assignments. Many tutors stated that they found it difficult to enter catching and appropriate thinking questions. At the end of the tutoring period, many tutors reported a better understanding of group dynamics, expressed a satisfactory feeling of belonging to a 'community', and reported a development in their reflective abilities. 
"In this final discussion theme, there is a reduced distance between me and the tutees. The interactions are less formal as well".

"Both the level of self-motivation and discussion ability are higher".

As a result, many tutors engaged in self-assessment and asked tutees for feedback about their personal tutoring approach. With respect to tutees' perceived evolution over time (12 statements over 9 interviews), tutors noted that the majority of the first-year students demonstrated sufficient technical skills to participate in the learning environments. Furthermore, the growth in unprompted tutee interaction with the tutor was appreciated. Finally, a gradual decline in the amount of meaningful tutee postings over time led some tutors to consider issues related to becoming tired, bored, and stressed, possibly connected to the demanding agenda of tutees.

"Compared to the beginning, they made less of an effort to get down to the bottom of a case."

\section{Tutor concerns}

In what follows, we present findings concerning the worries and dilemmas that emerged in 45 interviews with student tutors recalling the thought process underlying their tutoring approach in asynchronous discussion groups. Since 158 excerpts (over 35 interviews) were coded as 'tutor dilemma', tensions and feelings of uncertainty seem to be inherent to the induction period into online peer tutoring. Moreover, we focused on tutors' concerns as a way of better understanding relevant interventions and topics that may be useful for future training of online cross-age tutors. Five worries presented during the stimulated-recall interviews which should be further understood and better managed: (1) nature of intervention, (2) text-based interaction, (3) reasons for intervention, (4) amount of intervention, and (5) novice versus expert tutor role.

\section{Nature of intervention}

One of the key concerns refers to the idea that the tutor role is often limited to encouraging interaction between students. Even though the tutors knew they were expected to stimulate 'personal development' while e-moderating (Salmon, 2000), the tutors in our study expressed concern about both the complexity and lack of time preventing them from inviting tutees' critical thinking on the learning materials. More specifically, many tutors reported that the four two-weekly discussion assignments were rather extensive which made it difficult for them to ask the freshmen extra critical thinking questions as suggested in the preliminary training. This tutor concern led to thoughts of avoiding overloading the tutees when doing their best to complete the assignment on time. Hence, the necessary time for negotiating and completing the new body of knowledge in each group assignment must be considered in more detail.

\footnotetext{
"I asked a critical question and assured them that I did not intend to overburden someone."
}

Text-based interaction

Another worry that demands consideration is related to how student tutors approach their role in an online environment. In particular, this tutor dilemma involves the implications of written communication in CSCL, without face-to-face contact. Since this apprehension may be connected to the search for language adequacy and articulation within an electronic format, many tutors have doubts about how and when to intervene in order to facilitate purposively, concisely, and clearly. Being misinterpreted appears to be a major tutor concern as tutors are scared to discourage their tutees' enthusiasm to participate in the discussion, even when they contribute in a vague or far-fetched manner. 
"It is my ambition to write in as 'operant' a way as possible, I mean, so that they can value my contribution. I prefer to intervene in a formal and concrete way to let them build on my input."

\section{Reasons for intervention}

The third challenge concerns the tutors' worries associated with the multidimensional facilitating role in asynchronous discussion forums. Dependent on the task execution of the group, their knowledge construction, and their collaborative effectiveness, tutors can be situated in a context-specific role. For instance, the student tutors in the present study preferred not to jump in, make a comment, ask another question, or redirect the discourse when observing the discussion as progressing well. Conversely, in cases of misunderstanding or content mistakes, some tutors expressed a similar concern associated with the decision to intervene or not. More specifically, one tutor refers to the implications of making the decision to wait before redirecting the discourse as follows:

\footnotetext{
"In my opinion, giving my tutees the time to make and uncover content mistakes entails the diminishment of their time to discuss the right things."
}

\section{Amount of tutor intervention}

A fourth dilemma, partially related to the previous one, indicates the amount and frequency of postings necessary to call tutees' task-based interaction a 'good' discussion. A few tutors argued, regarding the input of both themselves and tutees', that:

\section{"Quantity is not intrinsic to quality, quite the contrary!"}

However, the overriding concern for the fourth-year students as they embarked upon the online tutoring process was whether they posted enough, not enough, or too much to bring or keep a meaningful discussion on track. Accordingly, in the early stages of their online facilitation practice, a few tutors expressed 'feeling of guilt' when considering to keep some time in the background. On the contrary, it appears that some tutors started by putting their own role in the learning environment into question:

\footnotetext{
"I did not want to be regarded as pedantic."

"From the beginning, I did not want to be regarded as teacher-like."
}

Novice versus expert tutor role

The final tutor concern is related to student tutors being a facilitator but not an expert in the learning materials they are expected to deal with. Tutors' focus of concern also includes a strong feeling of responsibility for tutees' learning and understanding in view of their exam. The following example provides evidence of the content-related uncertainty in peer tutors' reports.

\footnotetext{
"What if I add something wrong? I am not sure that my answer is right as I find the assignments quite difficult."
}

\section{General discussion}

The present study intended to explore the thoughts underlying the online facilitation acts of cross-age tutors in discussion groups. All tutors in this study were challenged by the demands of an online facilitation internship in higher education. From a set of 112 interviews, 45 interviews were chosen for data analyses. During a series of online tutoring activities, certain issues and concerns emerged that were of particular interest. The results indicate that there is 
more to learn when investigating tutors' online tutoring processes in relation to their underlying thoughts. Previous quantitative research in a similar academic context (De Smet et al., 2008) already showed that student tutors predominantly instantiated organizational and social support such as monitoring participation, providing technical help, and reinforcing good discussion behavior. In the present study, non-video stimulated-recall interviews generated tutor thoughts suggesting that the aforementioned result was not coincidental. The main points that arose from these interviews are summarized and discussed below.

Qualitative analysis of the tutor interviews revealed thoughtful and reflective attitudes. Regarding the validity of the stimulated-recall technique, the results of the present study are in line with previous research on teachers' interactive cognitions during teaching practice (Schepens, Aelterman, \& Van Keer, 2007). More specifically, the present study suggests that a transcript-based stimulated-recall technique can call on tutors' working memory when facilitating online, as was the case for teachers in a face-to-face context.

With regard to the first research question, the results of the interview analyses indicated six main issues. Initially, tutor reactions to the interview questions showed that online peer tutors have tutee-oriented reasons directing their decision to intervene in the discussion at a certain moment. An example is giving a compliment to the tutee prior to making a comment or posing a question. In this respect, the importance of providing a safe and non-threatening learning environment for participation in online communication and activities is stressed as an important guideline for future online and face-to-face peer tutoring settings and as a specific point of interest to deal with in tutor trainings. According to Henninger and Viswanathan (2004), the continuous social presence of a tutor seems to be critical in online tutoring in order to establish an interpersonal relationship and trust between the online communication partners. In addition, his or her social presence is critical to create a sense of community (Rovai, 2002; Swan, 2002).

The tutors' reasoning behind their decision not to intervene highlighted two arguments that are frequently found in the research literature. These arguments are based on socialconstructivist principles: 'not doing what they can do themselves' (Vygotsky, 1978) and 'leaving the discussion largely alone when there is good progress' (Mazzolini \& Maddison, 2007). In this respect, the stimulated-recall interviews with the tutors at the beginning and at the end of the tutoring period indicate that tutors intend to fade out their contributions and succeed in observing the ongoing discourse and in intervening only occasionally at the end of the tutoring period. However, they keep worrying about asking catching and reflective thinking questions. Similar concerns and a feeling of responsibility for ensuring that their peers addressed the tutorial objectives adequately were found in the empirical research of Solomon and Crowe (2001) on perceptions of student peer tutors in a PBL program. These results imply the importance of tackling these concerns during the preliminary tutor training and the interim support of the tutors in order to improve the practice of peer tutoring.

Many tutors further mentioned that they apply particular tutoring strategies when building an individual and deliberate relationship with their tutees. In line with the work of Sobral (2006), this finding suggests that there is a great variation among student tutors regarding personal goal-setting, frequency, and breadth of online tutoring activity. Notwithstanding these differences, it appeared that fourth-year tutors have at least two things in common. First, many tutors felt that both their good and bad experiences with online discussions are inspirational for acting in the role of an understanding and responsible cross-age tutor. Secondly, the in-service focus groups for tutors were perceived as a useful procedure to share experiences and to offer numerous ideas for improvements on one's tutoring performance.

With respect to the second research question, prominent dilemma components in the online tutoring processes were revealed. Although the focus of the study is on online peer tutoring, it should be mentioned, however, that the concerns raised by the peer tutors are not 
directly related to the 'online-ness' of the setting and also apply to offline, face-to-face peer tutoring contexts as well. The first concern and dilemma confirms the general conclusions of Chappell (1995) acknowledging that being a peer tutor is a complex process, especially with regard to acting in the role of 'peer' in conjunction with 'tutor'. In the current study, many tutor concerns are related to the continuous problem of deciding when and how to intervene due to a complex tutorial context that is simultaneously computer-supported, asynchronous, collaborative, cross-age, and task-based. Although there is clearly more research to be carried out, early indications suggested the following tutor concerns. At first it seemed that student tutors agree with Bennett and Marsh's (2002) idea that new information and communication technologies (ICT) have a considerable impact on the way in which people teach and learn. More specifically, connected to the online learning environment, being misinterpreted through written communication appears to be a main tutor concern as tutors are scared of discouraging tutees' enthusiasm to participate in the discussion when they contribute in a vague or farfetched manner. A second tutor dilemma is associated with the multidimensional, and therefore context-specific, facilitating role in asynchronous discussion forums (Mazzolini \& Maddison, 2007; Salmon, 2000). Even though they knew that they were trained to stimulate 'personal development' next to providing organizational and social support, a number of tutors in our study expressed two context-related problems inhibiting transfer of training (Ottoson, 1997; Saks, 1995). According to Ottoson (1997), transferability or perceived similarity between training and work environments assumes that "the context to which a skill transfers is one that supports or can accommodate the skill” (p. 89). In the present study, it appeared that both a lack of time and the complexity involved prevented our tutors from actually encouraging tutees' 'personal development' on the subject matter in the tutoring environment. These specific concerns about when and how to facilitate thinking skills are also consistent with the difficulties mentioned in previous research on teachers fostering critical thinking with a group of at-risk students in a face-to-face classroom setting (McBride \& Bonnette, 1995). The result is further in line with one of the concerns of trade union tutors involved in text-based online teaching (Bennett \& Marsh, 2002). A third and final major tutor concern is connected to the fact that peer tutoring involves tutors as facilitators, but not as experts in the learning materials they are expected to deal with. This result supports previous findings of Rourke and Anderson (2002) stating that a common anxiety about asking peers to assume the instructor role is their lack of content knowledge. Nevertheless, as pointed out by Topping (1996), peer tutoring typically has high focus on curriculum content. Paying extra attention to tutors' content knowledge in the preliminary tutor training might therefore assist them in their novice facilitator role. Other practical improvements can be made to the tutor training; for example, more information could be made available on the learning materials to be managed in the discussion group. In addition, examples of both 'good' collaboration and 'good' tutoring or facilitation practice within a CSCL-environment should be distributed for consideration by online peer tutors.

The presence of the blend of three prominent peer tutor dilemmas together with tutors' satisfaction regarding their received support point at the fact that attention should be drawn to providing a combination of pre- and in-service training support and guidance in order to optimize peer tutoring. Huberty and Davis (1998) and Hampel and Stickler (2005) stress the necessity to provide both pre-service and in-service support to online tutors as well. Tutor appreciation was especially related to the focus groups during which tutors got the opportunity to question and share experiences with peer tutors. The positive appreciation of the focus groups can be seen as a just-in-time way of providing tutors with training opportunities. This just-in-time nature has been repeatedly stated as beneficial in the context of training of complex skills (Kester, Kirschner, van Merrienboer, \& Baumer, 2001). This tutor learning dimension is also confirmed by Nath and Ross' (2001) who conclude that in- 
service tutor training efforts are important to ensure that peer tutors understand, integrate, and improve their tutoring skills during practice. It appeared that the in-service tutor training gave the tutors more self-confidence in tutoring. But also the training that was set up prior to the actual tutoring was considered to be important. The results point at the critical presence of sufficient time to discuss examples and time to practice and reflect on these experiences together with other novice tutors.

Notwithstanding the experienced dilemmas, time pressure, and the heavy workload, almost all student tutors involved in this study remained task-focused and motivated, persisting in their role even when some of their tutees seemed relatively discouraged at the end of the project because of the high workload so close to the examinations of the first semester. This responsible attitude of peer tutors corroborate the findings of Solomon and Crowe (2001) indicating that peer tutors convey a sense of worry and a feeling of responsibility for ensuring that their tutees addressed the tutorial objectives adequately. In general, during recalling their thoughts, the tutors demonstrated evidence of being active and self-regulated facilitators intending to bear in mind the internship as a meaningful learning experience for both themselves as tutors and for the freshman tutees.

\section{Limitations and further research}

The findings of this study, namely the thoughts and dilemmas associated with online facilitation, can be considered and adopted with their implications in the design of future online peer tutoring contexts. Moreover, tutors' input can be inspirational to the design and development of an adapted preliminary tutor training by higher institution educators. However, more empirical research is needed to confirm our findings. Future researchers might wish to understand the distinct as well as cumulative effects of task, training approach, group, and/or individual student variables on tutors' thoughts prior to and during performance. A number of factors which are not within the researcher's control could have influenced our resulting data. For example, it is feasible that the student tutors enrolled for this study vary on tutor-specific characteristics such as writing maturity, experience with group assignments, online experience and attitudes towards online interaction, and/or perceptions on academic internship affairs. Similarly, design characteristics of the present study, such as the co-tutoring format, tutors' prior experience in collaborating in asynchronous discussions, and tutor participation within an accredited module could have influenced the effectiveness of the preliminary training and interim focus groups, tutors' engagement, as well as tutors' thinking and the results of the present study. In this respect, future research should explore the impact of tutor differences, contextual circumstances, and the specific setting in more detail.

Another critical issue is related to the non-video stimulated-recall method as an element of a tutor training program. Although the student tutors reported that they were able to retrieve thoughts and decisions through stimulated recall on their text-based interventions in discussion groups, validating the degree of accuracy is very difficult as it seemed likely that they have brought a sense of semantic order to their verbal responses (Lyle, 2003). This methodological constraint was also recognized by Calderhead (1981) who argued that the stimulated-recall procedure and its explicit instructions prior to the task may encourage participants to place a greater degree of post-hoc rationality upon their behavior. Hence, we agree with researchers pointing to the small distinction between the 'recall of an event' and the 'reflection on an event' (Gass, 2001, In: Lyle, 2003). The support for tutors, as adopted in the current study, can however be criticized in view of this consideration. More specifically, whereas the focus groups for tutors, tutors' diary, and tutors' personal internship report aim at reflection on being an online peer tutor, the stimulated-recall interviews aim at recalling the event of being an online peer tutor. In future research, it would be recommended to 
distinguish between reflective and recalling internship goals in order to avoid interference. At the same time, it would be recommended to glance through the many different reasons for introducing stimulated-recall in education and educational research.

Since the present study is subject of a larger comparative study, it is further advisable to pursue methodological and data triangulation (Tashakkori \& Teddlie, 1998) using both qualitative and quantitative data and techniques. The stimulated-recall interview data reveal in-depth information about the thoughts and doubts of student tutors prior to and during performance, while quantitative research based on survey findings and/or content analysis could provide a knowledge base about the nature of tutor support. This idea follows the burgeoning interest in educational research utilizing mixed methods (Tashakkori \& Teddlie, 2003) and creates opportunities to go further than studying tutor thinking in isolation and independent from online group behavior. In this respect, the mutual relation between tutor and tutees and the important interplay between tutors' thinking and their actual behavior in the online discussions can be recognized and explored.

A final limitation of the present study is once again related to the reliability and validity issue in qualitative interpretative research. In our opinion, it would be interesting to give the results back to the student tutors in order to enhance the validity of our findings. By allowing them to read the researchers' interpretations related to the topics that arose during their retrospective talk, as a next step the participants could be given the opportunity to express more thoughts in order to refine the results.

\section{Acknowledgement}

This study was funded in part by the Flemish Government under the BOF program, 1107104.

\section{References}

Backroad Connections Pty Ltd. (2002). Effective Online Facilitation (Version 2.00), Australian Flexible Learning Framework Quick Guides series, Australian National Training Authority.

Bennett, S., \& Marsh, D. (2002). Are we expecting online tutors to run before they can walk? Innovations in Education and Teaching International, 39, 14-20.

Bonk, C. J., Wisher, R. A., \& Lee, J. Y. (2004). Moderating Learner-Centred E-Learning: Problems and Solutions, Benefits and Implications. In T. S. Roberts (Ed.), Online Collaborative Learning: Theory and Practice, 54-85. Hershey: Information Science Publishing.

Calderhead, J. (1981). Stimulated Recall: A Method for Research on Teaching. British Journal of Educational Psychology, 51, 211-217.

Carroll, M. (1996). Peer Tutoring: Can Medical Students Teach Biochemistry? Biochemical Education, 24, 13-15.

Chappell, V. A. (1995). Theorizing in Practice: Tutor Training "Live, from the VAX Lab". Computers and Composition, 12, 227-236.

Chi, M. T. H., Siler, S. A., \& Jeong, H. (2004). Can tutors monitor their students' understanding accurately? Cognition and Instruction, 22, 363-387.

Coyne, I. T. (1997). Sampling in qualitative research. Purposeful and theoretical sampling: merging or clear boundaries? Journal of Advanced Nursing, 26, 623-630.

Cutcliffe, J. R. (2000). Methodological issues in grounded theory. Journal of Advanced Nursing, 31, 1476-1484.

Darvin, J. (2006). "Real-world cognition doesn't end when the bell rings": Literacy instruction strategies derived from situated cognition research. Journal of Adolescent \& Adult Literacy, 50, 10-18. 
De Smet, M., Van Keer, H., \& Valcke, M. (2008). Blending Asynchronous Discussion Groups and Peer Tutoring in Higher Education: An Exploratory Study of Online Peer Tutoring Behaviour. Computers \& Education, 50, 207-223.

Dunkin, M. J., Welch, A., Merritt, R., Phillips, R., \& Craven, R. (1998). Teachers' Explanations of classroom events: Knowledge and beliefs about teaching civics and citizenship. Teaching and Teacher Education, 14, 141-151.

Duran, D., \& Monereo, C. (2005). Styles and sequences of cooperative interaction in fixed and reciprocal peer tutoring. Learning and Instruction, 15, 179-199.

Glaser, B. J., \& Strauss, A. L. (1967). The discovery of grounded theory: Strategies for qualitative research. New York: Aldine de Gruyter.

Hampel, R., \& Stickler, U. (2005). New Skills for new classrooms. Training tutors to teach languages online. Computer Assisted Language Learning, 18, 311 - 326.

Hargreaves, A., \& Fullan, M. (1998). What's Worth Fighting for Out There. New York: Teachers' College Press.

Henninger, M., \& Viswanathan, R. (2004). Social presence in online tutoring - What we know and what we should know. Proceedings of the first joint meeting of the EARLI SIGs Instructional Design and Learning and Instruction with Computers (CD-ROM). Tuebingen: Knowledge Media Research Center.

Huberty, C. J., \& Davis, E. J. (1998). Evaluation of a state critical thinking skills training program. Studies in Educational Evaluation, 24, 45-69.

Kagan, D. M. (1995). Research on teacher cognition. In A. C. Ornstein (Ed.), Teaching: Theory into Practice. Boston: Ally and Bacon.

Kester, L., Kirschner, P. A., Merrienboer, J. J. G., \& Baumer, A. (2001). Just-in-time information presentation and the acquisition of complex cognitive skills. Computers in Human Behavior, 17, 373-391.

Lave, J., \& Wenger, E. (1991). Situated Learning: Legitimate peripheral participation. Cambridge: Cambridge University Press.

Lyle, J. (2003). Stimulated Recall: A report on its use in naturalistic research. British Educational Research Journal, 29, 861-878.

Marsh, E. (2001). Atlas.ti, The Knowledge Workbench. Library \& Information Science Research, 23, 93-102.

Mazzolini, M., \& Maddison, S. (2007). When to jump in: The role of the instructor in online discussions forums. Computers \& Education, 49, 193-213.

McBride, R., \& Bonnette, R. (1995). Teacher and at-risk students' cognitions during openended activities: Structuring the learning environment for critical thinking. Teaching and Teacher Education, 11, 373-388.

McLuckie, J., \& Topping, K. J. (2004). Transferable skills for online peer learning. Assessment \& Evaluation in Higher Education, 29, 563-584.

Miles, M. B., \& Huberman, A. M. (1994). Qualitative data analysis. An expanded sourcebook. Thousand Oaks: Sage Publications.

Nath, L. R., \& Ross, S. M. (2001). The Influence of a Peer-Tutoring Training Model for Implementing Cooperative Groupings with Elementary Students. Educational Technology Research \& Development, 49, 41-56.

Ottoson, J. M. (1997). Beyond Transfer of Training: Using Multiple Lenses to Assess Community Education Programs. New Directions for Adult and Continuing Education, $75,87-96$.

Paulsen, M. F. (1995). Moderating Educational Computer Conferences, In Z. L. Berge and M. P. Collins (Eds.), Computer-mediated Communication and the On-line Classroom in Distance Education. Cresskill, NJ: Hampton Press. 
Rourke, L., \& Anderson, T. (2002). Using Peer Teams to Lead Online Discussions. Journal of Interactive Media in Education, 1, 1-21.

Rovai, A. (2002). Building Sense of Community at a Distance. International Review of Research in Open and Distance Learning, 4, 1-9.

Saks, A. M. (1995). Longitudinal field investigation of the moderating and mediating effects of self-efficacy on the relationship between training and newcomer adjustment. Journal of Applied Psychology, 80, 211-225.

Salmon, G. (2000). A model for CMC in education and training. E-moderating. The key to teaching and learning online. London: Kogan Page.

Samuelowicz, K. \& Bain, J. D. (2001). Revisting academics' beliefs about teaching and learning. Higher Education, 41, 299-235.

Schepens, A., Aelterman, A., \& Van Keer, H. (2007). Studying learning processes of student teachers with stimulated recall interviews through changes in interactive cognitions. Teaching and Teacher Education, 23, 457-472.

Seale, J. K., \& Cann, A. J. (2000). Reflection on-line or off-line: The role of learning technologies in encouraging students to reflect. Computers \& Education, 34, 309-320.

Sobral, D. (2006). Influences on choice of surgery as a career: A study of consecutive cohorts in a medical school. Medical Education, 40, 522-529.

Solomon, P., \& Crowe, J. (2001). Perceptions of student peer tutors in a problem-based learning programme. Medical Education, 23, 2, 181-186.

Stoffels, N. T. (2005). 'Sir, on what page is the answer?' Exploring teacher decision-making during complex curriculum change, with specific reference to the use of learner support material. International Journal of Educational Development, 25, 531-546.

Strauss, A., \& Corbin, J. (1990). Basics of Qualitative Research. Grounded Theory, Procedures, and Techniques. Sage Publications.

Swan, K. (2002). Building communities in online courses: the importance of interaction. Education, Communication and Information, 2, 23-49.

Tashakkori, A., \& Teddlie, C. (1998). Mixed methodology: Combining qualitative and quantitative approaches. Thousand Oaks: Sage Publications.

Tashakorri, A., \& Teddlie, C. (2003). Handbook of mixed methods in social \& behavioral research. Thousand Oaks: Sage Publications.

Topping, K. J. (1996). The effectiveness of peer tutoring in further and higher education: A typology and review of the literature. Higher Education, 32, 321-345.

Topping, K. J. (2005). Trends in Peer Learning. Educational Psychology, 25, 631-645.

Udvari-Solner, A. (1996). Examining Teacher Thinking. Remedial \& Special Education, 17, 245-255.

Valcke, M., Sang, G., Rots, I., \& Hermans, R. (in press). Taking prospective teachers' beliefs into account in teacher education. In E. Baker, B. McGaw, and P. Peterson (Eds.), International Encyclopedia of Education, 3rd edition, pp. xxx-yyy. Oxford: Elsevier.

Vygotsky, L. S. (1978). Mind in society: The development of higher psychological processes. Cambridge, MA: Harvard University Press.

Webb, N. M. (1992). Testing a theoretical model of student interaction and learning in small groups. In R. Hertz-Lazarowitz and N. Miller (Eds.), Interaction in cooperative groups. Cambridge: Cambridge University Press.

Wigfield, A., \& Eccles, J. S. (2000). Expectancy-value theory of achievement motivation. Contemporary Educational Psychology, 25, 68-81.

Zafeiriou, G. (2003). Managing conflict and reaching consensus in text-based computer conferencing: The students' perspective. Education for Information, 21, 97-111.

Zohar, A., Degani, A., \& Vaaknin, E. (2001). Teachers' beliefs about low-achieving students and higher order thinking. Teaching and Teacher Education, 17, 469-485. 